\title{
Comparison of proximal femoral nail antirotation (PFNA) with AO dynamic condylar screws (DCS) for the treatment for unstable peritrochanteric femoral fractures
}

\author{
Emrah Kemal Şahin • Ahmet İmerci • \\ Hakan Kınık • Levent Karapınar · Umut Canbek • \\ Ahmet Savran
}

Received: 20 November 2012/ Accepted: 13 February 2013/Published online: 27 February 2013

(C) The Author(s) 2013. This article is published with open access at Springerlink.com

\begin{abstract}
Purpose The aim of this study was to compare the results of intramedullary fixation with those of plate-screw fixation for peritrochanteric femoral fracture patients older than 60 years old.

Methods This article reports on a retrospective review of patients who had peritrochanteric femoral fractures and were treated with a $95^{\circ}$ fixed-angle screw plate (DCS) or an intramedullary nailing system (PFNA). Patients with 79 fractures were enrolled in the study; 47 of them were treated with the PFNA system and 37 with the DCS. Followed for at least 1 year, the treatment groups were compared by taking into consideration all demographic and trauma variables.
\end{abstract}

E. K. Şahin · A. İmerci ( $₫)$

Department of Orthopaedics and Traumatology, Erzurum

Palandoken State Hospital, Asag1 Kosk Mah. Yakutiye,

Erzurum 25100, Turkey

e-mail: ahmet_dr81@hotmail.com

E. K. Şahin

e-mail: emrahkemalsahin@yahoo.com

H. Kınık

Department of Orthopaedics and Traumatology,

Ankara University School of Medicine, Mesa Koru Sitesi,

Fulya Blok No: 44, Cayyolu, Ankara, Turkey

e-mail: hakankinik12@yahoo.com

L. Karapınar · A. Savran

Department of Orthopaedics and Traumatology, Izmir Tepecik

Education and Research Hospital, Izmir 35000, Turkey

e-mail: lkarapinar@yahoo.com

U. Canbek

Department of Orthopaedics and Traumatology, Mugla Sitk1

Kocman University School of Medicine, Mugla, Turkey

e-mail: umutcanbek@hotmail.com
Results No significant differences were discovered between the two groups with regard to side of injury, mechanism of trauma, associated comorbidities, AO fracture classification, average follow-up duration, mortality, and fracture reduction quality at the 1-year follow-up. The average surgical time was significantly lower in the PFNA group (57 min.) compared to the DCS group ( $87 \mathrm{~min}$.). Longer operative time was needed in the DCS group, and thus, greater blood loss occurred compared to the PFNA group. The functional results of the PFNA group were found to be significantly better than those of the DCS group.

Conclusions Owing to some advantages, such as minimal exposure, reduced operative blood loss, and the achievement of biological fixation, PFNA is a better choice for the treatment for unstable peritrochanteric fractures.

Keywords Peritrochanteric fractures - Proximal femoral nail antirotation - Dynamic condylar screws .

Intramedullary fixation - Extramedullary fixation

\section{Introduction}

Because life expectancy has increased worldwide in recent years, a considerable increase has occurred in the incidence of proximal femoral fractures [1]. These fractures usually result from minor traumas. Complications with peritrochanteric fractures arise primarily from fixation rather than union or delayed union because the peritrochanteric area is made up of spongious bones [2]. The aim of the surgery is to achieve early mobilization and to quickly return the patient to pre-surgery activity levels. However, the treatment for these fractures continues to be difficult for surgeons [3]. 
The best treatment for unstable peritrochanteric fractures is still a subject of debate [4]. Various implants have been designed to facilitate fracture fixation, obtain early ambulation, and reduce the risk of complications in the treatment for peritrochanteric fractures $[5,6]$. These implants can be divided into two groups: intramedullary and extramedullary [5-9]. To achieve rotational and angular stability, in 2004, the proximal femoral nail antirotation (PFNA) device, one of the third-generation intramedullary implants (PFNA; Synthes ${ }^{\circledR}$ Oberdorf, Switzerland), was developed by the AO/ASIF group. PFNA blades have been biomechanically proven to compact cancellous bone and achieve increased stability and thus to delay rotation and varus collapse. Biomechanical tests have also indicated significantly higher cutout resistance in osteoporotic bone compared to other widely used screw systems [6, 10-12]. The sliding hip screw has become the most widely used extramedullary implant in the treatment for hip fractures $[6,13,14]$. Some investigators, however, have reported that this implant is not proper for unstable fractures, and these investigators have supported various alternative methods of fixation for these more difficult types of fractures $[14,15]$. The DCS, an implant of extramedullary fixation, which was modified from the $95^{\circ}$ fixed-angle plate by the AO/ASIF group, is much easier to apply in that location because its screw is cannulated [16, 17].

The purpose of this retrospective study was to compare the results of the DCS and the PFNA in the treatment for unstable peritrochanteric fractures in patients older than 60 .

\section{Patients and methods}

This observational study enrolled patients who were treated in our hospital with the DCS and the PFNA for peritrochanteric fractures between January 2007 and December 2010. The inclusion criteria were radiologically diagnosed unstable peritrochanteric fractures (31-A2 and -A3 for $\mathrm{AO} / \mathrm{ASIF}$ classification), age older than 60 years old, and an American Society of Anesthesiologists (ASA) score of 1-4. The exclusion criteria were pathologic fractures, poor ambulation before the trauma, polytrauma, and severe concomitant medical conditions (ASA 5). The patients underwent surgery 4-10 days (mean, 6 days) after admission. The patients were divided into two groups. Intramedullary fixation with the PFNA system (Synthes ${ }^{\circledR}$ Oberdorf, Switzerland) was implemented in Group A $(n=42)$. This group was composed of 42 patients with peritrochanteric fractures (AO Classification: 31-A2 in 23 and 31-A3 in 19). Group B $(n=37)$ underwent extramedullary fixation with the DCS system (Synthes ${ }^{\circledR}$ Oberdorf, Switzerland). This group consisted of 37 patients with peritrochanteric fractures (AO Classification: $31-\mathrm{A} 2$ in 21 and $31-\mathrm{A} 3$ in 16).
For all of the patients, background variables, including age, gender, associated comorbidities, and mechanism of trauma, were recorded. Postoperative clinical assessments were conducted using the Salvati and Wilson [18] scoring system. The number of units of blood transfused intraoperatively and postoperatively was recorded in each group (hct $<27 \%$ ).

Surgery was implemented as soon as the patients' general health conditions were suitable. Surgeons who had performed the PFNA and DCS procedures at least three times performed the operations. All of the patients were administered a preoperative intravenous injection of antibiotic cefuroxime $(1 \mathrm{~g})$, and general or spinal anesthesia was used in both groups. All of the fractures in Group A were treated on the operating table in a lateral decubitus position under the control of C-arm fluoroscopy, and the fractures were reduced and treated with closed reductions. The patients in Group B were treated in a supine position with open methods under the control of C-arm fluoroscopy. Antibiotic treatments continued for 2 postoperative days. The extent of anatomical reduction $(<5)$ was classified as acceptable $\left(5^{\circ}-10^{\circ}\right.$ varus/valgus and/or anteversion/retroversion) or poor ( $>10$ varus/valgus and/or anteversion/ retroversion). Rehabilitation was started as early as possible after surgery, and the patients were allowed to bear as much weight as they could tolerate. All of the patients were regularly examined physically and radiographically after 6 weeks and at 3, 6, and 12 months after their operations. Radiographs of the operated hip were obtained at each follow-up visit, and the position of the implant and extent of fracture union were noted.

\section{Statistical analyses}

Statistical analysis was performed using two tests. Student's $t$ tests were used to compare the two groups with regard to mean age, surgical time, mean follow-up duration, units of blood transfused, partial weight-bearing time, Salvati-Wilson Hip Score, and consolidation time. $\chi^{2}$ analyses were performed to compare the groups with regard to gender, side of injury, mechanism of injury, associated comorbidities, AO fracture classification, mortality at 1-year follow-up, fracture reduction quality, and complications. A difference was considered to be statistically significant when $p<0.05$.

\section{Results}

The etiological reasons, in order of incidence, for treatment were falls and traffic accidents, and fall frequency was not statistically significant $(p=0.39)$. The mean surgical time for patients treated with PFNA was $57 \mathrm{~min}$ (range 
Table 1 Comparison of the main characteristics of the patients included in the study and the outcomes obtained using the PFNA and the DCS devices

\begin{tabular}{|c|c|c|c|}
\hline & $\begin{array}{l}\text { PFNA } \\
\text { (Group A; } n=42 \text { ) }\end{array}$ & $\begin{array}{l}\text { DCS } \\
\text { (Group B; } n=37 \text { ) }\end{array}$ & $p$ values \\
\hline Gender: male/female & $17 / 25$ & $18 / 19$ & 0.46 \\
\hline Age (years): mean (range) & $77.02 \pm 7.88$ & $72.05 \pm 5.80$ & $<0.05$ \\
\hline Side: right/left & $19 / 23$ & $17 / 20$ & 0.95 \\
\hline \multicolumn{4}{|l|}{ Mechanism of injury } \\
\hline Simple fall at home & 34 & 27 & 0.39 \\
\hline Traffic accident & 8 & 10 & \\
\hline \multicolumn{4}{|l|}{ Associated comorbidities } \\
\hline Hypertension & 10 & 8 & 0.67 \\
\hline Diabetes & 7 & 7 & \\
\hline Cardiovascular disease & 3 & 4 & \\
\hline Neurological disease & 3 & 3 & \\
\hline \multicolumn{4}{|l|}{ AO fracture classification } \\
\hline A2 & 23 & 21 & 0.85 \\
\hline A3 & 19 & 16 & \\
\hline Surgical time (min) & $57.69 \pm 17.47$ & $87.86 \pm 23.71$ & $<0.05$ \\
\hline Mean follow-up period (months) & $20.67 \pm 5.32$ & $23.19 \pm 7.22$ & 0.07 \\
\hline Blood transfused (units) (erythrocyte suspensions) & $0.21 \pm 0.42$ & $1.78 \pm 1.08$ & $<0.05$ \\
\hline Partial weight-bearing (days) & $7.28 \pm 3.97$ & $22,27 \pm 10.72$ & $<0.05$ \\
\hline Mortality at 1-year follow-up & 4 & 6 & 0.37 \\
\hline Salvati-Wilson Hip Score (maximum points 40) & $31.04 \pm 4.64$ & $26.11 \pm 4.97$ & $<0.05$ \\
\hline Consolidation time (weeks) & $15.71 \pm 5.49$ & $22.59 \pm 10.21$ & $<0.05$ \\
\hline
\end{tabular}

32-96 min) and was significantly lower than in those treated with DCS, in which the mean time was 87 (range 64-178) min $(p<0.05)$. The mean Salvati-Wilson hip score on final evaluation was 31 in the PFNA group, and in the DCS group, it was 26 ( $p<0.05)$. In the group treated with the PFNA, the time for consolidation was significantly shorter compared to the DCS group $(p<0.05)$. In terms of associated comorbidities, no significant differences were seen between the two groups ( $p=0.67)$ (Table 1).

Fracture reduction was considered good or acceptable in 69 patients (37 PFNA, 32 DCS) on postoperative radiographs. There were no significant differences between the quality of reduction for both implants and fracture types $(p=0.83)$ (Table 2).

The orthopedic and general postoperative complications are listed in Table 3. No significant differences were seen between the two groups in terms of orthopedic or general complications ( $p=0.10$ and $p=0.57$, respectively). The mortality rate at 1 year was $9.5 \%$ in the PFNA group, compared with $16.2 \%$ in the DCS group. There was no statistically significant difference between the two groups in terms of the 1-year mortality rate $(p=0.37)$.

In Group A, 37 patients experienced satisfactory reduction and fixation and were able to undertake early weight-bearing. In Group B, 12 patients were able to bear weight early, although 32 patients experienced satisfactory reduction (Figs. 1, 2).
Table 2 Quality of fracture reduction and postoperative radiographic evaluation

\begin{tabular}{lclc}
\hline & PFNA (\%) & DCS $(\%)$ & $p$ value \\
\hline Fracture reduction quality $(\%)$ & & \\
Good & 73.9 & 70.2 & 0.83 \\
Acceptable & 14.2 & 16.3 & \\
Poor & 11.9 & 13.5 & \\
\hline
\end{tabular}

Table 3 Distribution of patients with complications according to the internal fixation devices

$\begin{array}{lll}\text { PFNA } & \text { DCS } & p \text { values } \\ (n=42, \%) & (n=37, \%) & \end{array}$

Orthopedic complications

Lateral migration of blade or screw

0.1

Cut-out 2

Nonunion $\quad 0 \quad 1$

Infection $\quad 1 \quad 3$

Implant failure $\quad 0 \quad 2$

Reoperation $\quad 2 \quad 4$

General complications

$\begin{array}{llll}\text { Symptomatic DVT } & 1 & 2 & 0.57\end{array}$

Decubitus $\quad 0 \quad 1$

Pneumonia $\quad 1 \quad 1$

Urinary infection $\quad 2 \quad 1$



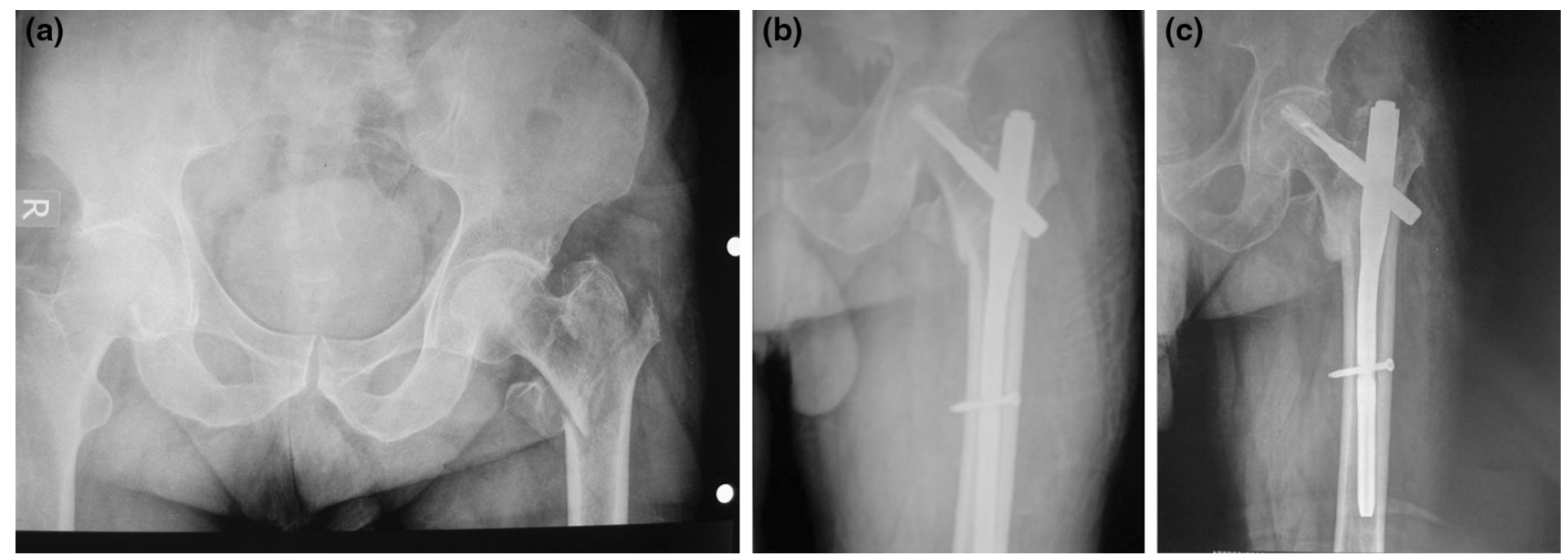

Fig. 1 Seventy-six-year-old female patient sustaining an isolated and closed 31-A2 fracture at the left side (a) after a simple fall. Postoperative X-ray after closed reduction and internal fixation with a PFNA (b). Final anteroposterior hip radiograph at the 12-month follow-up (c)
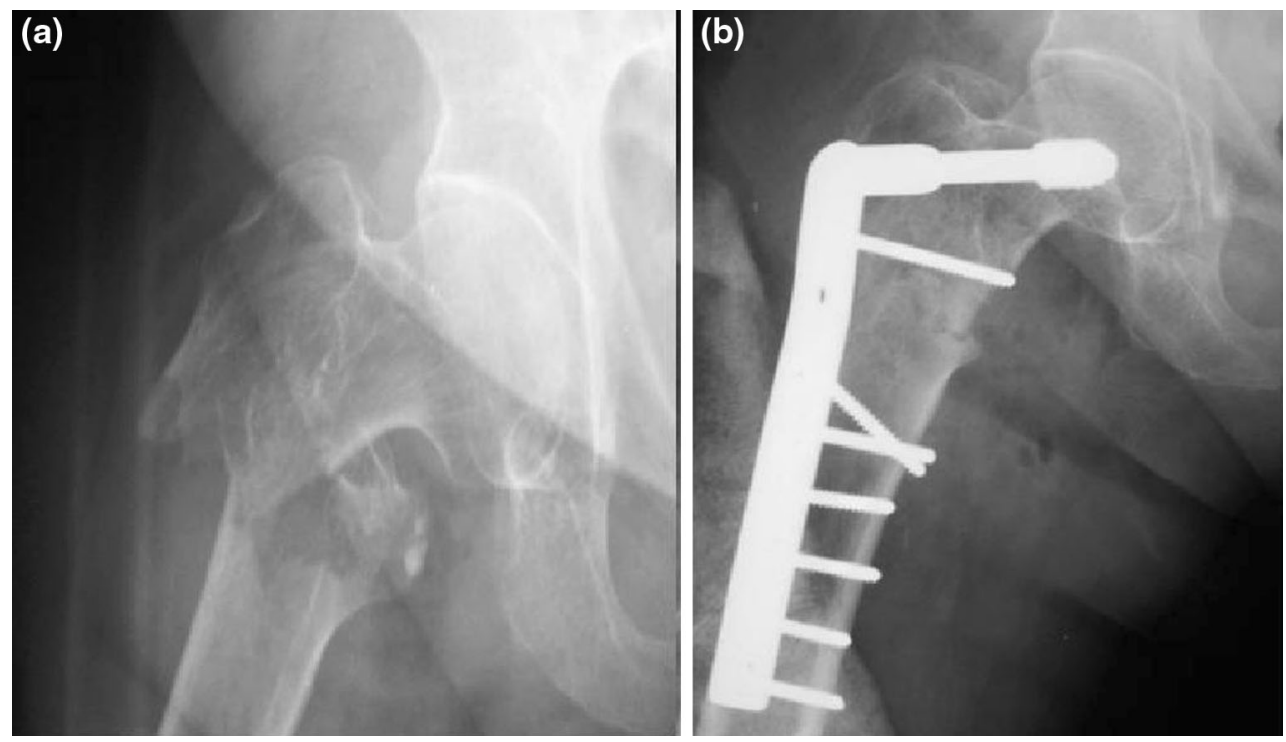

Fig. 2 a Anteroposterior radiograph of the right hip of a 76-year-old female who fell in the street, revealing an 31-A3 peritrochanteric fracture. b Post op radiographs after open reduction and extramedullary fixation with a DCS

\section{Discussion}

It is predicted that peritrochanteric femoral fractures will increase greatly in the coming years. Failure rates due to complications are still considerable, although the implants and surgical techniques have improved greatly. Rigid internal fixation combined with early mobilization is still considered the gold standard. The functional results might not be satisfactory because of failure to heal or failure of fixation, although a wide range of techniques are in use. The implants used can be partly responsible for the results. Sliding hip screws, as well as blade plates, dynamic condylar screws (DCS), and the formerly used intramedullary devices, have been found to be problematic [19]. That intramedullary devices might be superior to plating systems in unstable proximal femoral fractures has been shown in biomechanical examinations [20].

Because it produces a small bending moment, the PFNA system acts as an internal splint, and at the same time, it can bear a large axial load. Along with this ability, the helical blade of the PFNA system enhances its bone purchase in the femoral neck-head. Additionally, the blade prevents rotation or compaction of the proximal fragment by locking with the nail rotationally. These factors allow the patient to bear partial weight sooner after surgery $[12,21,22]$. Another important advantage of the PFNA technique is that it can be performed with minimal surgical invasion. Some disadvantages of this technique include 
cutout of the implant and femoral medialization. Lateral migration of proximal screws or helical blades is also a complication with this implant [11, 23-25].

The DCS is an implant designed by the AO/ASIF Group for use in proximal and distal femoral fractures. This device has been proved to have some technical advantages over the AO condylar blade plate [17]. DCS plates provide the ability to produce a range, especially in the sagittal plan, of rotation of the proximal part of the lag screw. However, it is obvious that many complications have been observed after surgeries. The most important of these complications are devascularization, seen as a result of over-dissection, union delay, failure to unify, and infection $[26,27]$. The deficiency and fatigue of the implant should also be considered [17, 28, 29].

In our study, it was observed that the time to partial weight-bearing on the associated extremity in the DCS group was significantly longer than in the PFNA group $(p<0.05)$. In addition, the patients operated on with the DCS were more often advised to avoid sudden full weightbearing, and because the fracture fixation was not considered stable enough, there was no satisfactory fracture impaction postoperatively $[30,31]$. Open reduction and intramedullary fixation have been suggested as the first choice, regardless of age, in intertrochanteric fractures in which the medial colon is intact. IM nails, with their biomechanical features, have come into prominence in some types of unstable peritrochanteric fractures $[4,22]$. In a study by Sadowski et al. [14], AO Type III patients were examined, and it was found that implant deficiency occurred in one case in the PFNA group. In our study, no significant differences between the two groups regarding orthopedic complications were detected.

The DCS used in this technique was cheaper and more widely available in our country than other techniques. There are important stages in the technique, such as appropriate placement of the guide wire and slipping of the plate over the lag screw, and these stages can be simplified using the technique explained here. Provided that the technique is performed correctly, the success rate is high [32]. As such, the technique has an important role in patients with good bone stock.

In contrast, the DCS as an extramedullary fixation device was an alternative to "intramedullary fixation" for proximal and distal femoral fracture fixations [32], although the PFNA is the gold standard for the stabilization of the femoral neck and for most peritrochanteric fractures [11, 12]. The profits of intramedullary nailing are more commonly observed than with the extramedullary procedure, which often requires reoperation due to technical problems [12].

In our series, femoral head or neck perforation was observed in three patients (3.7 \%). The DCS was used in one of these patients and the PFNA in two. The rates of femoral head perforation were found to be $1.4 \%$ in a study by Karapınar et al. and $1.2 \%$ in a study by Simmermaher et al. $[12,23]$. In a study by Sadowski et al. [14], the rates of cutout were noted as 26.3 and $5 \%$, respectively. In our study, the reasons for cutout in the PFNA group were related to technical failure. The blade was not in the desired central position but in the anterosuperior position. Perforation was observed in patients with the DCS because of early weight-bearing.

There are very few studies comparing intramedullary fixation with angular stable plates for the treatment for unstable fractures [14]. As in many articles in the literature, sliding hip screw devices have been compared with the PFNA in the treatment for all types of unstable intertrochanteric fractures $[6,8,25]$. In our study, there were limitations inherent in the methodology used because it was a retrospective, controlled study.

\section{Conclusion}

The main objective of the management of elderly patients with peritrochanteric fractures is a successful return to safe mobility. In our study, the radiographic parameters were the same between the two groups. Nevertheless, intraoperative parameters, such as simpler technique, minimal exposure, shorter surgical time, reduced blood loss, and postoperative functional parameters, demonstrated that the PFNA is a more effective device for the management of peritrochanteric fractures, compared to the DCS.

\section{Conflict of interest None.}

Open Access This article is distributed under the terms of the Creative Commons Attribution License which permits any use, distribution, and reproduction in any medium, provided the original author(s) and the source are credited.

\section{References}

1. Xu YZ, Geng DC, Mao HQ, Zhu XS, Yang HL (2010) A comparison of the proximal femoral nail antirotation device and dynamic hip screw in the treatment of unstable pertrochanteric fracture. J Int Med Res 38(4):1266-1275

2. Akıncı O, Akalın Y, Reisoğlu A, Kayalı C (2010) Comparison of long-term results of dynamic hip screw and AO 130 degrees blade plate in adult trochanteric region fractures. Acta Orthop Traumatol Turc 44(6):443-451. doi:10.3944/AOTT.2010.2356

3. Pu JS, Liu L, Wang GL, Fang Y, Yang TF (2009) Results of the proximal femoral nail anti-rotation (PFNA) in elderly Chinese patients. Int Orthop 33(5):1441-1444. doi:10.1007/s00264-0090776-3

4. Jones HW, Johnston P, Parker M (2006) Are short femoral nails superior to the sliding hip screw? A meta-analysis of 24 studies involving 3, 279 fractures. Int Orthop 30:69-78

5. Utrilla AL, Reig JS, Muñoz FM, Tufanisco CB (2005) Trochanteric gamma nail and compression hip screw for trochanteric fractures: a randomized, prospective, comparative study in 210 
elderly patients with a new design of the gamma nail. J Orthop Trauma 19(4):229-233

6. Zeng C, Wang YR, Wei J, Gao SG, Zhang FJ, Sun ZQ, Lei GH (2012) Treatment of trochanteric fractures with proximal femoral nail antirotation or dynamic hip screw systems: a meta-analysis. J Int Med Res 40(3):839-851

7. Zou J, Xu Y, Yang H (2009) A comparison of proximal femoral nail antirotation and dynamic hip screw devices in trochanteric fractures. J Int Med Res 37(4):1057-1064

8. Garg B, Marimuthu K, Kumar V, Malhotra R, Kotwal PP (2011) Outcome of short proximal femoral nail antirotation and dynamic hip screw for fixation of unstable trochanteric fractures. A randomised prospective comparative trial. Hip Int 21(5):531-536. doi:10.5301/HIP.2011.8657

9. Saarenpää I, Heikkinen T, Ristiniemi J, Hyvönen P, Leppilahti J, Jalovaara P (2009) Functional comparison of the dynamic hip screw and the Gamma locking nail in trochanteric hip fractures: a matched-pair study of 268 patients. Int Orthop 33(1):255-260. doi:10.1007/s00264-007-0458-y

10. PFNA (2004) Leading the way to optimal stability: synthes. Original instruments and implants of the Association for the Study of Internal Fixation. AO/ASIF. Stratec Medical, Oberdorf, pp 1-44

11. Mereddy $P$, Kamath S, Ramakrishnan M, Malik H, Donnachie N (2009) The AO/ASIF proximal femoral nail antirotation (PFNA): a new design for the treatment of unstable proximal femoral fractures. Injury 40(4):428-432. doi:10.1016/j.injury.2008.10.014

12. Karapınar L, Kumbaracı M, Kaya A, İmerci A, İncesu M (2011) Proximal femoral nail anti-rotation (PFNA) to treat peritrochanteric fractures in elderly patients. Eur J Orthop Surg Traumatol 5:1-7. doi:10.1007/s00590-011-0810-1

13. Hardy DC, Descamps PY, Krallis P, Fabeck L, Smets P, Bertens CL, Delince PE (1998) Use of an intramedullary hip-screw compared with a compression hip-screw with a plate for intertrochanteric femoral fractures. A prospective, randomized study of one hundred patients. J Bone Joint Surg Am 80:618-630

14. Sadowski C, Lübbeke A, Saudan M, Riand N, Stern R, Hoffmeyer P (2002) Treatment of reverse oblique and transverse intertrochanteric fractures with use of an intramedullary nail or a 95 degrees screw-plate: a prospective, randomized study. J Bone Joint Surg Am 84-A(3):372-381

15. Haidukewych G, Israel A, Berry D (2001) Reverse obliquity fractures of the intertrochanteric region of the femur. J Bone Joint Surg Am 83:643-650

16. Müller ME, Allgöwer M, Schneider R, Willenegger H (1991) Manual of internal fixation. Springer, Berlin, pp 270-281

17. Schatzker J, Mahomed N, Schiffman K, Kellam J (1989) Dynamic condylar screw: a new device. A preliminary report. J Orthop Trauma 3(2):124-132

18. Salvati EA, Wilson PD Jr (1973) Long-term results of femoralhead replacement. J Bone Joint Surg Am 55(3):516-524

19. Liu Y, Tao R, Liu F, Wang Y, Zhou Z, Cao Y, Wang H (2010) Mid-term outcomes after intramedullary fixation of peritrochanteric femoral fractures using the new proximal femoral nail antirotation (PFNA). Injury 41(8):810-817. doi:10.1016/ j.injury.2010.03.020

20. Curtis MJ, Jinnah RH, Wilson V, Cunningham BW (1994) Proximal femoral fractures: a biomechanical study to compare intramedullary and extramedullary fixation. Injury 25(2):99-104

21. Takigami I, Matsumoto K, Ohara A, Yamanaka K, Naganawa T, Ohashi M, Date K, Shimizu K (2008) Treatment of trochanteric fractures with the PFNA (proximal femoral nail antirotation) nail system-report of early results. Bull NYU Hosp Joint Dis 66(4):276-279

22. Kristek D, Lovrić I, Kristek J, Biljan M, Kristek G, Sakić K (2010) The proximal femoral nail antirotation (PFNA) in the treatment of proximal femoral fractures. Coll Antropol 34(3): 937-940

23. Simmermacher RK, Ljungqvist J, Bail H, Hockertz T, Vochteloo AJ, Ochs U, Werken C, AO-PFNA studygroup (2008) The new proximal femoral nail antirotation (PFNA) in daily practice: results of a multicentre clinical study. Injury 39(8):932-939. doi: 10.1016/j.injury.2008.02.005

24. Sahin S, Ertürer E, Oztürk I, Toker S, Seçkin F, Akman S (2010) Radiographic and functional results of osteosynthesis using the proximal femoral nail antirotation (PFNA) in the treatment of unstable intertrochanteric femoral fractures. Acta Orthop Traumatol Turc 44(2):127-134. doi:10.3944/AOTT.2010.2237

25. Xu Y, Geng D, Yang H, Wang X, Zhu G (2010) Treatment of unstable proximal femoral fractures: comparison of the proximal femoral nail antirotation and gamma nail 3. Orthopedics 33(7):473

26. Radford PJ, Howell CJ (1992) The AO dynamic condylar screw for fractures of the femur. Injury 23(2):89-93

27. Konstantinidis L, Papaioannou C, Mehlhorn A, Hirschmüller A, Südkamp NP, Helwig P (2011) Salvage procedures for trochanteric femoral fractures after internal fixation failure: biomechanical comparison of a plate fixator and the dynamic condylar screw. Proc Inst Mech Eng H 225(7):710-717

28. Neogi DS, Trikha V, Mishra KK, Rohilla N, Yadav CS (2009) Biological plate fixation of comminuted subtrochanteric fractures with the dynamic condylar screw: a clinical study. Acta Orthop Belg 75(4):497-503

29. Vaidya SV, Dholakia DB, Chatterjee A (2003) The use of a dynamic condylar screw and biological reduction techniques for subtrochanteric femur fracture. Injury 34:123-128

30. Yoo MC, Cho YJ, Kim KI, Khairuddin M, Chun YS (2005) Treatment of unstable peritrochanteric femoral fractures using a 95 degrees angled blade plate. J Orthop Trauma 19(10):687-692

31. Zhang CL, Zeng BF, Dong Y, Terrell D, Malawer MM (2008) Dynamic condylar screw or hip joint (spanning) external fixator for treatment of pathological fractures of femoral neck and trochanter secondary to benign lesions. Chin Med J (Engl) 121(2): 178-180

32. Ort PJ (1990) Dynamic condylar screw: a new device. J Orthop Trauma 4(1):105 